BMJ Nutrition,

Prevention \& Health

\title{
Literacy is power: structural drivers of child malnutrition in rural Liberia
}

\author{
Odell W Kumeh, ${ }^{1,2}$ Mosoka P Fallah, ${ }^{3}$ Ishaan K Desai, ${ }^{1,4}$ Hannah N Gilbert, ${ }^{1}$ \\ Jason B Silverstein, ${ }^{1}$ Sara Beste, ${ }^{5,6}$ Jason Beste, ${ }^{5,7}$ Joia S Mukherjee, ${ }^{1,4}$ \\ Eugene T Richardson (1) ${ }^{1,4}$
}

To cite: Kumeh OW, Fallah MP, Desai IK, et al. Literacy is power: structural drivers of child malnutrition in rural Liberia. $B M$ Nutrition, Prevention \& Health 2020;3:e000140. doi:10.1136/ bmjnph-2020-000140

${ }^{1}$ Department of Global Health and Social Medicine, Harvard Medical School, Boston, Massachusetts, USA

${ }^{2}$ Ministry of Health of Liberia, Monrovia, Montserrado, Liberia ${ }^{3}$ National Public Health Institute of Liberia, Monrovia, Montserrado, Liberia

${ }^{4}$ Partners In Health, Boston,

Massachusetts, USA

${ }^{5}$ Partners In Health, Harper, Liberia

${ }^{6}$ Division of Emergency Medicine, Seattle Children's Hospital, Seattle, Washington, USA

${ }^{7}$ Department of Global Health, University of Washington, Seattle, Washington, USA

Correspondence to Dr Eugene T Richardson, Department of Global Health and Social Medicine, Harvard Medical School, Boston, MA 02115, USA;

eugene_richardson@hms. harvard.edu

Received 13 July 2020 Revised 5 October 2020 Accepted 13 October 2020 Published Online First 1 December 2020

Check for updates

(c) Author(s) (or their employer(s)) 2020. Re-use permitted under CC BY-NC. No commercial re-use. See rights and permissions. Published by BMJ.

\section{ABSTRACT}

Background In Liberia, an estimated $32 \%$ of children under 5 are stunted. Malnutrition and hunger worsened during the country's civil war and were further exacerbated by the 2014-2016 outbreak of Ebola virus disease. Studies examining adherence to recommended infant and young child feeding practices frequently do so with an emphasis on the knowledge, attitudes and beliefs of mothers and caregivers. Often overlooked are the structural factors that enable or constrain their agency to practise evidencebased recommendations.

Methods Between July and December 2017, we surveyed 100 Liberian mothers to assess the sociodemographic factors associated with the risk of severe acute malnutrition in children in Maryland County, Liberia. We also conducted 50 in-depth interviews at two government health facilities to qualitatively explore mothers' experiences, as well as health workers' understandings of the determinants of malnutrition in the region. We applied logistic regression to analyse quantitative data and inductive content analysis to thematically interpret qualitative data

Results Mothers were less likely to have a child with severe acute malnutrition if they had an income greater than US $\$ 50$ per month (adjusted OR $(\mathrm{aOR})=0.14$, $p<0.001)$, were literate $(a O R=0.21, p=0.009)$ or exclusively breast fed during the first 6 months of life $(\mathrm{aOR}=0.18, \mathrm{p}=0.049)$; they were more likely to have a child with severe acute malnutrition if they were married or in domestic partnerships $(\mathrm{aOR}=8.41, \mathrm{p}<0.001)$. Indepth interviews elucidated several social, economic and programmatic factors that shaped suboptimal feeding practices, as well as decisions for and against seeking formal care for malnutrition.

Discussion The lived experiences of Liberian mothers and health workers illustrate that child malnutrition is a direct consequence of abject poverty, food insecurity, illiteracy, the precarious nature of formal and informal work, and the lack of robust social protection. Behaviour change and health education interventions that do not seek to alleviate structural barriers to compliance are unlikely to be effective.

\section{BACKGROUND}

The 'inalienable right to be free from hunger and malnutrition' was enshrined over four decades ago in the Universal Declaration on the Eradication of Hunger and Malnutrition ${ }^{1}$

\section{What this paper adds}

- Quantitative and qualitative methods were used to study the social and economic factors related to child malnutrition in Liberia, transcending reductionistic assessments of nutritional knowledge and beliefs.

- Having a child with severe acute malnutrition was inversely associated with maternal literacy, but not with maternal level of education.

- 'Non-compliance' with recommended child nutritional practices in Liberia was found to be driven more by poverty, an absence of social support, and gender inequity than by shortcomings in health education.

and reaffirmed in the 1996 Rome Declaration on World Food Security. ${ }^{2}$ More recently, the United Nations underscored the global fight against hunger and malnutrition by incorporating it within the Sustainable Development Goals endorsed in 2015-'Goal 2: end hunger, achieve food security and improved nutrition, and promote sustainable agriculture ${ }^{3}$ - and by proclaiming the years 20162025 as the 'Decade of Action on Nutrition'. Despite several years of steady progress, however, the Food and Agriculture Organization announced in 2017 that global hunger had increased since 2015, with several parts of the world at risk for the "worst food crisis since the Second World War'.

Malnutrition is synergistic with other biosocial drivers of child morbidity and mortality. Undernutrition is an underlying cause of an estimated $50 \%$ of deaths in children under the age of $5 .{ }^{6}$ Chronic malnutrition leads to stunting-being too short for one's agewhich affects physical health and has cognitive impacts, which can make succeeding academically or escaping poverty more difficult; malnutrition thus affects human capital and economic development. ${ }^{7}$ Adequate nutrition during the first 1000 days of life-between conception and a child's second birthday-is 
considered especially important, as stunting in early life can have long-term physical, cognitive, economic and health effects. ${ }^{8-10}$ Early initiation and maintenance of breast feeding-including exclusive breast feeding during the first 6 months of life, as recommended by the $\mathrm{WHO}^{11}$ — can significantly reduce childhood morbidity and mortality and is thus a highly promoted intervention for programmes combating malnutrition. ${ }^{12} 13$

The World Bank reports that $85 \%$ of the global burden of stunting is concentrated in just 37 countries, one of which is Liberia. ${ }^{14}$ In Liberia, childhood underweight and suboptimal breast feeding are the two leading risk factors underlying the nation's total disease burden; various micronutrient deficiencies-including iron, vitamin A and zinc-rank among the top 15 risk factors. ${ }^{15}$ Liberia's 2013 Demographic and Health Survey found that 32\% of children under 5 were stunted (short for age), $6 \%$ were wasted (thin for height) and $15 \%$ were underweight (thin for age); in rural regions, these proportions were found to be $33 \%, 6 \%$ and $17 \%$, respectively. ${ }^{16}$ Only $55 \%$ of infants under 6 months of age were exclusively breast fed, and the median duration of exclusive breast feeding was just 2.7 months (3.2 months in rural areas). Among children between 6 and 23 months of age, only $4 \%$ were nourished according to three nationally recommended infant and young child feeding practices related to breast feeding status, diversity of diet and frequency of meals; in rural areas, only $3 \%$ of children were fed according to these recommendations. ${ }^{16}$ Food insecurity and malnutrition worsened during the country's devastating civil war, ${ }^{1718}$ and were further exacerbated in the region by its 2014-2016 outbreak of Ebola virus disease. ${ }^{19-21}$ Nevertheless, biosocial research on the issue of childhood malnutrition in Liberia is lacking.

Studies investigating the factors that influence breast feeding and other child feeding practices in settings of abject poverty (including in others parts of West Africa) often do so from cognitivist perspectives, seeking to evaluate the knowledge, attitudes and beliefs of mothers and caregivers and correlating them with nutrition-associated behaviours and outcomes. ${ }^{22-43}$ Public health programmes, in turn, frequently implement campaigns to raise nutritional awareness and knowledge, with the intention of improving health behaviours. Less attention has been paid, however, to the structural factors that enable or constrain the agency of mothers and caregivers to practise evidence-based recommendations for the promotion of child nutrition, health and development. In low-income, postconflict countries with high maternal mortality, such as Liberia, ${ }^{44}$ such structural factors may contribute more significantly to the burden of child malnutrition than the presumed ignorance or lack of health education among familial or professional caregivers.

We therefore conducted a mixed-methods study to examine the sociodemographic factors associated with the risk of severe acute malnutrition among children in rural south-eastern Liberia, and to qualitatively explore mothers' experiences of breast feeding, accessing nutritionally adequate food and seeking medical treatment for malnourished children, as well as health workers' understandings of the determinants of malnutrition in the region. The findings can improve our understanding of the structural drivers of paediatric malnutrition in Liberia and inform recommendations for improving the nutritional status of Liberian children.

\section{METHODS}

\section{Setting}

This case-control study took place at J J Dossen Hospital and Pleebo Health Center in Maryland County, Liberia. Owned by the Government of Liberia and supported by the non-governmental organisation Partners In Health, these two clinical sites are the largest health facilities in Maryland County and draw patients from much of south-eastern Liberia, with J J Dossen Hospital serving as a referral centre for the region. They are also among the few health facilities in Maryland County that provide services for acute malnutrition.

\section{Study design and data collection}

We employed a mixed-methods, sequential explanatory, case-control design, in which quantitative data were collected and analysed, and qualitative methods were then used to contextualise and further explore the quantitative findings. ${ }^{45}$ Data collection occurred between July 2017 and December 2017 at J J Dossen Hospital and Pleebo Health Center.

The quantitative portion of the study involved the administration of a survey questionnaire to mothers of malnourished children and mothers of non-malnourished children to collect sociodemographic data (numerical and categorical) on children's age and gender and on mothers' age, marital status, place of residence, education level, employment status, income, food security, general literacy (ability to read a hospital poster), receipt of maternal and child nutrition education during pregnancy and breast feeding practices (including frequency, duration, exclusivity during first 6 months of life, time of initiation and weaning, and complementary/supplemental feeding during first 6months). Children were considered 'malnourished' in this study if they met at least one of three WHO-recommended diagnostic criteria for severe acute malnutrition: a weight-for-height z-score less than -3 SD of WHO child growth standards, a midupper arm circumference (MUAC) less than $115 \mathrm{~mm}$ and/or the presence of bilateral pitting oedema related to nutritional status. ${ }^{46}{ }^{47}$ Children were considered 'nonmalnourished' if they had a MUAC greater than or equal to $125 \mathrm{~mm}$ or a weight-for-height z-score greater than -1.5 $\mathrm{SD}^{48}$

A convenience sample of 100 participants was constructed by recruiting 50 mothers with malnourished children (25 cases from each clinical site) and 50 mothers with non-malnourished children (25 controls from each clinical site) consecutively, in order of presentation to the 
health facility, on days when the investigator was on-site at J J Dossen Hospital or Pleebo Health Center. (A sample size of 100 was selected based on the rule of thumb that 10 participants per predictor variable are adequate to power regressions; the survey entailed 10 predictor variables.) Children were initially evaluated by a physician in the outpatient department, and their mothers were subsequently invited to participate in the questionnaire if interested. Children found to be malnourished were referred for additional care and evaluation in the nutrition department of J J Dossen Hospital or Pleebo Health Center. As regards inclusion criteria, women were eligible to participate in the survey if they resided in the catchment areas of the respective clinical sites for at least 2 years and if their child was between 0 and 2 years of age, negative for HIV or tuberculosis and brought to J J Dossen Hospital and Pleebo Health Center for care during the study period. The questionnaire was independently developed by the study team and the clinical leads for Partners In Health, and designed to include sociodemographic factors understood to be relevant based on literature review of the determinants of child malnutrition in low-income countries. The collected data were used to identify factors associated with the risk of severe acute malnutrition.

The qualitative portion of the study involved semistructured, in-depth interviews with mothers of malnourished children, mothers of non-malnourished children and health workers from each of the study's clinical sites. Twenty mothers of malnourished children (10 from each clinical site) and 20 mothers of non-malnourished children (10 from each clinical site) were interviewed; they were recruited from the questionnaire sample and were eligible for interview if they lived in Maryland County for at least 2 years. Lastly, 10 health workers working in the nutrition department (five from each clinical site) were interviewed; they included nine clinical nurses and one social worker. Interviews followed semistructured interview guides for each group (see table 1) and used an iterative process that facilitated the development of further probes and questioning. All interviews were conducted by the first author, audiotaped with permission, transcribed and subsequently compared against audio recordings to ensure accuracy. Transcripts were maintained in Liberian English.

\section{Data analysis}

Statistical data collected from the questionnaire (numerical and categorical) were analysed using logistic regression, with child nutritional status as the dependent variable (malnourished vs non-malnourished). Covariates were evaluated through a purposeful selection process: those with a $p$ value $\leq 0.2$ in univariate analyses were included in the adjusted multivariate model to identify factors significantly associated with nutritional status $(\mathrm{p}<0.05) .{ }^{49}$ Data were analysed using STATA/IC V.15.1 (StataCorp, College Station, Texas).

Qualitative data analysis followed an inductive, contentanalytic approach that elicited a set of key descriptive themes from the experiential narratives of mothers and health workers. ${ }^{50} \mathrm{~A}$ subset of interviews was used to develop an initial set of codes, which was revised to develop a codebook. The resultant codebook was used to direct code all transcripts with the support of Dedoose qualitative data analysis software. Coded data were iteratively examined to construct key thematic categories concerning infant and young child feeding practices,

\begin{tabular}{|c|c|}
\hline Study participant & Topics of discussion \\
\hline Mothers & $\begin{array}{l}\text { Antenatal care and nutritional support received during most recent pregnancy } \\
\text { Types of food consumed while pregnant } \\
\text { Household food security } \\
\text { Access to safe and nutritionally adequate foods } \\
\text { Health education received during and after pregnancy } \\
\text { Experiences of breast feeding and complementary feeding since delivery } \\
\text { Reasons for or against breast feeding } \\
\text { Personal and family perceptions of breast feeding and its relation to child's health } \\
\text { Daily jobs and social obligations and their relation to child's nutritional status } \\
\text { Challenges to adhering to recommended infant and young child feeding practices in postnatal } \\
\text { period }\end{array}$ \\
\hline
\end{tabular}


Table 2 Characteristics of surveyed mothers in Maryland County, Liberia, by nutritional status of child (malnourished, $\mathrm{n}=50$; non-malnourished, $\mathrm{n}=50$ )

\begin{tabular}{lll}
\hline & $\begin{array}{l}\text { Malnourished } \\
\text { child } \\
\mathbf{n}(\%)\end{array}$ & $\begin{array}{l}\text { Non- } \\
\text { malnourished } \\
\text { child } \\
\mathbf{n}(\%)\end{array}$ \\
\hline $\begin{array}{l}\text { Age (years) } \\
\leq 25\end{array}$ & $22(44)$ & $32(64)$ \\
$>25$ & $28(56)$ & $18(36)$ \\
\hline $\begin{array}{l}\text { Marital status } \\
\text { Single/divorced/widowed }\end{array}$ & $13(26)$ & $32(64)$ \\
\hline Married/domestic partnership & $37(74)$ & $18(36)$ \\
\hline $\begin{array}{l}\text { Education level } \\
\text { None or primary school }\end{array}$ & $39(78)$ & $23(46)$ \\
\hline Junior high or senior high level & $11(22)$ & $27(54)$ \\
\hline Income & & $14(28)$ \\
\hline$<U S \$ 50$ per month & $33(66)$ & $36(72)$ \\
\hline$>$ US $\$ 50$ per month & $17(34)$ & $25(50)$ \\
\hline Literate & & $25(50)$ \\
\hline Yes & $9(18)$ & \\
\hline No & $41(82)$ & \\
\hline
\end{tabular}

Exclusive breast feeding during first 6 months of child's life

\begin{tabular}{ccc} 
Yes & $35(70)$ & $46(92)$ \\
No & $15(30)$ & $4(8)$ \\
\hline
\end{tabular}

food insecurity and clinical care for severe acute malnutrition in rural south-eastern Liberia.

\section{RESULTS}

Select sociodemographic characteristics of the 100 Liberian mothers who were surveyed are presented in table 2 and categorised by child's nutritional status (malnourished vs non-malnourished, as previously defined). Participants were between 18 and 50 years of age. Their children were between 0 and 24 months old; 54 children were male and 46 were female.

After employing the process of purposeful selection of variables, ${ }^{49}$ maternal age, marital status, education level, income, general literacy, adherence to exclusive breast feeding during the first 6 months of life and clinical site remained as covariates. In the ensuing multivariate logistic regression model (table 3), marital status, income, general literacy and adherence to exclusive breast feeding were found to be significantly associated with child malnutrition $(p<0.05)$. Specifically, mothers who were married or in domestic partnerships had higher odds of having a malnourished child (adjusted OR $(\mathrm{aOR})=8.41, \mathrm{p}<0.001)$, while those who had an income greater than US $\$ 50$ per month $(\mathrm{aOR}=0.14, \mathrm{p}<0.001)$ or were literate $(\mathrm{aOR}=0.21$, $\mathrm{p}=0.009$ ) had lower odds of having a malnourished child. An inverse association between exclusive breast feeding and severe acute malnutrition was also observed $(\mathrm{aOR}=0.18, \mathrm{p}=0.049)$.

Qualitative data analysis revealed several contextual factors shaping suboptimal breast feeding and complementary feeding practices, mothers and children's limited access to nutritious foods and decisions to seek (or not to seek) medical care for malnourished children. These themes are summarised in table 4 and described in greater depth below.

\section{Factors shaping suboptimal breast feeding and complementary feeding practices}

Limited feasibility of exclusive breast feeding within mothers' social and economic contexts

Per national and WHO-endorsed guidelines for infant and young child feeding, mothers who attended antenatal clinics at J J Dossen Hospital and Pleebo Health Center were instructed to exclusively breast feed their children for the first 6 months of life and to introduce safe and nutritionally adequate complementary foods at 6 months, along with continued breast feeding up to 2 years of age. However, several mothers who were interviewed introduced other liquids and solid foods within the first months of life, even though many felt that premature introduction of complementary foods may have had negative effects on their infants' health. Health workers commented on an association of this practice with malnutrition. One nurse, for example, stated:

When I get to know the age, then I ask the parents which one of the food the child is eating. For some

\begin{tabular}{|c|c|c|c|}
\hline Characteristic & Adjusted OR & $95 \% \mathrm{Cl}$ & $P$ value \\
\hline Age (>25 years) & 1.87 & 0.61 to 5.71 & 0.270 \\
\hline Marital status (married/domestic partnership) & 8.41 & 2.46 to 28.82 & $<0.001$ \\
\hline Education level (junior high level or above) & 0.56 & 0.18 to 1.74 & 0.317 \\
\hline Income (>US\$50 per month) & 0.14 & 0.05 to 0.45 & $<0.001$ \\
\hline Literate & 0.21 & 0.06 to 0.68 & 0.009 \\
\hline Exclusive breast feeding (first 6 months of child's life) & 0.18 & 0.03 to 0.99 & 0.049 \\
\hline Clinical site (J J Dossen Hospital) & 2.39 & 0.77 to 7.42 & 0.13 \\
\hline
\end{tabular}


Table 4 Summary of themes from qualitative data analysis

\begin{tabular}{|c|c|}
\hline Main theme & Associated factors \\
\hline $\begin{array}{l}\text { Suboptimal breast feeding and } \\
\text { complementary feeding practices }\end{array}$ & $\begin{array}{l}\text { Informal jobs with limited security, leaves, pay, childcare support, } \\
\text { accommodations, or maternity support } \\
\text { Distance to farms precludes sustained contact between mothers and children } \\
\text { School and other vocational commitments reduce young mothers' proximity to } \\
\text { infants } \\
\text { Insufficient economic and/or social support from husbands or male partners } \\
\text { Misconceptions about colostrum and its safety } \\
\text { Community-based outreach and public messaging }\end{array}$ \\
\hline $\begin{array}{l}\text { Limited access to nutritious foods for } \\
\text { mothers and children }\end{array}$ & $\begin{array}{l}\text { Low wages and incomes restrict quantity and quality of procured foods } \\
\text { Social obligations of mothers to feed entire families, not just vulnerable children } \\
\text { Frequent choice of cheaper, nutrient-poor foods over nutritionally adequate ones } \\
\text { to increase quantity }\end{array}$ \\
\hline
\end{tabular}

of the babies, they start giving them food soon. From zero to six months, they are only supposed to be on taytay water [breast milk], but some of the parents can start giving the children food sooner, sometimes at three or fourmonths. Some of the food they give the children they can't prepare it good; that's why they come down with malnutrition. (Health worker at J J Dossen Hospital)

Collectively, mothers who did not exclusively breast feed provided a few key reasons to explain why. Some were young women who had babies before they were able to finish junior high or senior high school. Returning to school or vocational training required separating themselves from their infants and entrusting infant care to other caregivers, often their own mothers:

After this time, I will transfer her to her grandmother-my mother-and I will start school. I need to go to school to have a good future for me and my children. I don't want my family to suffer. (Mother of a malnourished child at JJ Dossen Hospital)

They stated that school attendance forced them to breast feed infrequently and be away from their infants for extended periods of time, impeding lactation. One nurse described a correlation between the duration of time a mother spent at school and her child's risk of malnutrition:

When you asked the mother, 'Why you are not breastfeeding the child?', they tell you, 'I am in school.' The mother tells you how much time in school. When they come back, "breastfeeding the child is hard, so the breast milk is dried, and I can't breastfeed.' That's why the child is malnourished. (Health worker at J J Dossen Hospital)

Multiple mothers pointed to the economic burdens they carry as their families' primary breadwinners and caregivers. With responsibilities to feed and financially support their families, many women felt that exclusive breast feeding for a 6 -month period was not feasible within their social contexts and material constraints. Jobs and informal work with limited security, leaves, pay, childcare support, accommodations or maternity support left mothers unable to tend to their babies as frequently as needed and led them to initiate complementary feeding prematurely. The time-intensive search for piecemeal work-or 'hustle' - separated mothers from children for long periods, impeding mothers' capacity to breast feed young infants:

Babies' mothers do not have the means to buy food. Some of them have to hustle to find food to eat. Sometimes at the end of the day they do not have any food to eat, and so they go without breastfeeding the child, and they boiled water and force the child to drink it. (Health worker at Pleebo Health Center)

Some health workers stated that poorer Liberian mothers, in an effort to find food for family, leave children at home for many hours or in the care of community members. Many, for example, have small plots of land that they farm, which are typically situated far from their homes. To procure produce from these plots, women may leave their children at home during the day and are 
unable to breast feed or respond to their children's nutritional needs on a consistent and reliable basis. A social worker specialising in nutritional and vaccination services surmised that children who are left unattended in this manner are more vulnerable to malnutrition:

There are some parents who cannot afford to feed their children on a daily basis regularly. Some go to check for something for the children to eat all day long and leave the child home. They go, and before they come back, it is the evening time. The child is not eating well, and the child is not taken care of. At the end, the child becomes malnourished. These children have poor home care. Most of the parents usually go on the farm and leave the children at home and return after noon before they decide to find food for the children. (Health worker at Pleebo Health Center)

Furthermore, several mothers felt they lacked the accompaniment they needed from family members to exclusively breast feed and that that they did not receive much in the way of financial or social support from male partners after pregnancy. Some also noted that their partners had various external financial obligations-toward extended families, for example-which diminished their contributions to feeding the nuclear family:

I have three children, and I do not have the support from their fathers. I have to work to bring food home for us to eat. I go soon in the morning and come home late in the evening. I can't breastfeed the baby for whole sixmonths, the time the nurse told me, because my family have to eat. When I get money, I buy milk sometimes. Most of the times I can cook the rice or fufu soft and give it to her. If no milk, I give her water. I started doing this when she was fourmonths. (Mother of a malnourished child at Pleebo Health Center)

At the same time, some women who had completed secondary or tertiary schooling felt that their educational status permitted them greater leeway in demanding social and economic contributions from their male partners.

\section{Views on colostrum and delayed initiation of breast feeding}

While educational, work and familial obligations were the most common explanations for the impracticability of exclusive breast feeding, some interviewees also pointed to popular beliefs and misconceptions about breast feeding in the region. Some mothers explained that they avoided feeding their children colostrum - the first form of milk, produced immediately after birth, which is very nutritious and rich in antibodies-because they felt that it was diseased and could cause harm or even death; to protect their children, they delayed the initiation of breast feeding well beyond the recommended time frame of within 1 hour after delivery. One attributed the death of a previous child to the receipt of colostrum and stated that this experience drove her to avoid breast feeding her current child:
This is my second child. The first child was breastfed for five months and died at eleven months. I did not breastfeed my second child because I am afraid before the child die. I don't know if that's the taytay water I gave make her to die. So, I am not giving this baby taytay because I am scare. She is ten months but too small and weak. I have been bringing her to the hospital, and the doctor say she is malnourished because I did not give her taytay when she was small, and I started giving her food too soon. (Mother of a malnourished child at J J Dossen Hospital)

Health workers likewise reiterated that myths about colostrum were widespread in the region, including the idea that its yellowish hue is a sign of ill health. Said one nurse:

They feel that the first breast milk is not good for the baby, and this milk is the colostrum and has all the vitamins within it. Some of them feel that the first breast milk has disease in it, and they refused to give it to the child. Therefore...the child is deprived of that breast milk, and they wait for a certain length of time to breastfeed the child. And as a result, they start to introduce water to the baby at an early age. (Health worker at Pleebo Health Center)

In an effort to alter misconceptions about colostrum and breast milk, Liberian health authorities, community health workers and international partners have organised and implemented public awareness and outreach initiatives. One recent campaign, sponsored by the Ministry of Health of Liberia and UNICEF and executed by the nutrition unit of the Maryland County Health Team, offered workshops on the topic at county health facilities. Radio promotion was also conducted by the Ministry of Health to publicly underscore the nutritional and immunological benefits of protein-rich and antibody-rich colostrum. Some mothers explained that messaging on the radio and at health workshops helped them understand the importance of colostrum for infant health and thereby comply with recommended breast feeding practices:

On UNMIL radio, you can hear them saying, 'Baby ma, when you give birth, give the baby taytay water.' And they say the first taytay water [colostrum] is good for the baby. I can hear it. That's how I managed to know, and I gave it to my baby. I also learned from a workshop that they have for the mothers concerning the yellow taytay water [colostrum]. We were told to give the baby the first taytay water, which is yellow because it is very good for the baby. (Mother of a nonmalnourished child at J J Dossen Hospital)

\section{Factors shaping mothers and children's limited access to nutritious foods}

Inadequate income to feed children and families

Mothers of malnourished children expressed a continual struggle to obtain and afford sufficient amounts of food for their children and their families. Some searched for contracts to wash clothes or clean the yards of others for 
meagre financial compensation. Women detailed the laborious and chronically uncertain means by which they gathered income to feed their large families:

We are nine in the house. At times, we buy only one kilo of rice, so we share it, small, small. We manage it, so you can just have something to taste and you manage to sleep. Sometimes I used to eat with my neighbor because I never had food. (Mother of a malnourished child at Pleebo Health Center)

In spite of long hours of work, many mothers reported that their family could eat only once per day. Moreover, they said that financial constraints forced them to choose nutrient-poor foods such as farina and cassava to sustain themselves and their families:

I always never had enough to eat. Sometimes, when we cook in the morning and I eat, then I will eat farina in the evening because no money to cook good food. When I have money, I can buy tea and drink it in the night before I sleep. We only used to cook one time during the whole day. (Mother of a malnourished child at J J Dossen Hospital)

Nurses working in public facilities shared similar views, citing job and income insecurity as the primary drivers of the poor outcomes they often observe among their paediatric patients:

Most often, when you ask why this child is malnourished, they [mothers] will always tell you they do not have enough food to eat, they are not working, and at the end of the month there is no earning or salary to purchase food for the family. Instead, every day, they go on the hustle to find some kind of work to enable them to find food for their family. (Health worker at Pleebo Health Center)

\section{Sale or sharing of supplemental therapeutic foods}

Qualitative interviews suggested that children treated for malnutrition on an inpatient basis are at heightened risk for relapse when they return to a home environment characterised by severe deprivation. After discharge from public health facilities in Liberia, malnourished children are given ready-to-use therapeutic foods (RUTFs) and/or other supplemental fortified foods for recovery. However, mothers reported that when they returned home with a malnourished child, they were compelled to divide RUTFs supplied by the health facility among other children or family members in the household. In other cases, these rations were sold to meet other needs:

Let me speak the truth: the food they gave me for my child at the hospital is enough, but it can finish soon because I can give some to my other children in the house. The peanut butter [RUTF], we all can eat it. Sometimes when I am not around, the children can take it from behind me and eat it. This is some of the reason the girl is not getting well fast, and she is still in the malnourished program. (Mother of a malnourished child at JJ Dossen Hospital)

Nurses confirmed this trend, emphasising that when children do not receive prescribed RUTFs at home, their health and nutritional status can quickly deteriorate. They also reported that some mothers do not bring children back to the clinic when relapse occurs because they are ashamed of their inability to adhere to recommended therapeutic feeding regimens. While several nurses expressed frustration over this phenomenon, most also recognised the social and financial pressures experienced by mothers to sell or share RUTFs, acknowledging the roles that shame and stigma may play in exacerbating paediatric malnutrition:

What we noticed about the relapse is that when they go home, the way you tell them to give the food they are not giving it. Some of them even sell the food because they need money because some of them are from a poorincome family. They say if I sell few of these things given to me from the hospital, I will be able to buy rice for us to eat, so they sell it. The quantity of RUTF the child is supposed to eat the child is not eating it, and so the child starts to deteriorate. When the child deteriorates, most say I was ashamed to come back to the hospital because I ate the RUTF or I sold the RUTF. (Health worker at Pleebo Health Center)

\section{Factors shaping decisions to seek medical care for malnourished children \\ Reasons for seeking facility-based care for malnutrition}

Some mothers who had attended antenatal clinic at Pleebo Health Center or J J Dossen Hospital were very receptive to the nutritional education they received. They indicated that the relationships they formed with clinicians and social workers during pregnancy increased their confidence in the health facility and its staff, leading them to more frequently seek care for their child after delivery-for malnutrition and for other ailments as well. This confidence also appeared to motivate women to advise others within their communities to seek formal care when needed. For example, one mother who was interviewed reported that she sought treatment for her malnourished children because another woman who had had positive experiences at J J Dossen Hospital encouraged her to do so:

One of my friends advised me and said, 'the way this boy is getting sick, why can't you carry him to clinic so you can explain it to the people that he stopped sucking because he is still small and he needs to continue to be sucking taytay. Go and explain it to them so they can see what they can do.' That's how I brought him to the clinic. (Mother of a malnourished child at J J Dossen Hospital)

Facility-based health workers lauded the efforts of community health workers to promote nutritional 
education, early identification of acute malnutrition and referral services. They affirmed that the mothers of many of their patients had reported to the clinic because of the support they had received from community health workers:

The community health workers are in the community creating awareness and using placards. Some babies' mothers that have benefited from this program, along with some photos, see the progressions that have been made with these children. If we continue this, most people will come to the hospital and the rate of malnutrition will reduce. (Health worker at J J Dossen Hospital)

Campaigns run by community health workers thus appeared to be an important source of knowledge about acute malnutrition and provided pathways for seeking prompt care. Mothers noted that community health workers taught them how to identify the signs and symptoms of acute malnutrition, as had other cadres of lay and traditional health workers, allowing for earlier presentation. Decentralised programmes for the early detection of malnutrition were also cited by mothers as reasons for their enrolling children in government-sponsored malnutrition programmes:

My child had been sick, and I have been taking him to the drug store and didn't know what was happening to him. From the posters and the different things the people talked, I just felt my son had the sickness they were talking about. I brought my son, and the people put the tape around his hand, and they told me he was malnourished and I should bring him to the hospital. That was why I brought him, and they put him in the program. We can come for food every week, and this is helping him. (Mother of a malnourished child at Pleebo Health Center)

\section{Reasons for not seeking facility-based care for malnutrition}

On the other hand, some mothers who were interviewed explained that they felt ashamed to bring their child to the hospital because they anticipated being criticised by friends or health workers for their failure to nourish their child. Some mothers were also pregnant again; they worried they would be judged for not spacing their pregnancies. According to this subset of interviews, such concerns initially dissuaded some mothers against bringing their malnourished children to the hospital:

My child has been sick for more than one month, but I was ashamed to come to the hospital because this is my second child with this same sickness [severe acute malnutrition]. In my area [community], the people can always talk to me saying I cannot take good care of my children. When I go to the hospital and I see the people from my area, I can be ashamed. I can feel they have discussed me with the nurse, and I don't want the nurse to quarrel with me. The nurses have also advised me about taking care of my children. For this reason, I was scared to bring this other child. I really brought the baby today because she is very weak, and the nurse say they will put her in the malnourished program and give us food. (Mother of a malnourished child at Pleebo Health Center)

The effects of stigmatisation on mothers' care-seeking decisions were corroborated from the perspectives of health workers as well. A nurse at JJ Dossen Hospital, who met one such mother in the community, explained:

Some of them will be bold and tell you, 'I was ashamed; that was why I did not come earlier.' I ask one of the mothers whose child was malnourished, and she uprightly told me she was ashamed to come to the hospital because she was pregnant, and her child was too dry and not looking good. She said she was seven months pregnant, and the child was less than twoyears. She was even crying when she was explaining and said she was embarrassed. Some of them are ashamed because some of them are pregnant, and these children are malnourished. To hold that child to come to the hospital, they feel ashamed that their peer group will laugh at them and say, 'oh, their child hasn't walk, and she is pregnant.' So actually, to bring these children is not an easy thing. (Health worker at J J Dossen Hospital)

Additionally, signs of childhood malnutrition were occasionally viewed by communities as evidence of witchcraft. When physical manifestations of malnutrition are interpreted as such, noted some mothers and health workers, women may preliminarily seek assistance from a traditional healer or a 'church yard'-a sacred place where patients seek prophetic healing when they believe an illness is unrelated to a biomedical condition:

My child was very sick. I took her to the hospital, and she was not getting well as I expected. She was given the malnourished food treatment but was still skinny. I decided to take her to the church yard because what was happening to her the doctors could not help me cure her. She was bewitched by some people in the community. I took her to the church yard for healing. It really didn't help me, so I came to beg the doctor to please help my child to get well. (Mother of a malnourished child at JJ Dossen Hospital)

Facility-based clinicians also explained that, in some cases, the remedies children are given in church yards may be unhelpful or even serve to worsen their condition. Said one nurse:

When the child is malnourished and the feet are swollen up and the stomach is big, they [family members and the traditional healers they consult] believe that it is food poison. In these situations, sometimes they go to the extent of giving the child herbs. Sometimes, they find herbalist that will give the child enema, and 
lots of herbs to drink that will not do the child any good. (Health worker at JJ Dossen Hospital)

\section{DISCUSSION}

This study applied a mixed-methods, biosocial analysis to investigate the determinants of child malnutrition in rural Liberia, with an emphasis on the lived experiences of caregivers (mothers and professional health workers). Imperial legacies, extractive industries, structural adjustment, purposeful underdevelopment, enabled civil war and flawed aid policies are important macrosocial causes of hunger and disease in Liberia. ${ }^{51-61}$ This study sought a more granular, microsocial description of malnutrition by examining how large-scale forces are manifested in the everyday experiences of mothers and children, and how they shape food insecurity, treatment for severe acute malnutrition and adherence to recommended infant and young child feeding practices, among other related issues.

We found that mothers with higher monthly incomes (>US\$50) were less likely to have a malnourished child. The link between poverty and child malnutrition is documented in other studies from sub-Saharan Africa. ${ }^{62-66}$ In-depth interviews helped elucidate the mechanisms by which poverty structures the circumstances of Liberian mothers and heightens the risk of acute malnutrition in their children (and of poor outcomes once malnourished). We observed, for example, that poverty was the most cited driver of mothers' inability to exclusively breast feed and of premature initiation of complementary feeding. Specifically, unreliable jobs with meagre pay, security and maternity accommodations forced many mothers to spend extended periods of time away from their infants-including on farms situated far from their households-in search of food and income. This precluded the sustained contact needed between mother and child to regularly breast feed. Efforts to overcome their poverty-by returning to school (in the case of younger mothers) or vocational training, for examplelikewise caused separation; with little to no savings, many poor mothers lamented that they had to resume school or work too soon after delivery. Inadequate income also restricted the quantity and nutritious quality of foods they could procure for their children and limited the number of daily meals they could provide. Poverty even compelled mothers to sell or share RUTFs and supplemental foods prescribed specifically for a malnourished child. Our study documented that this was a common mechanism of relapse among malnourished children treated at J J Dossen Hospital and Pleebo Health Center.

Importantly, nearly every mother interviewed knew that she should exclusively breast feed for the first 6 months of her child's life, continue to breast feed once complementary foods are introduced and avoid distributing RUTFs to others. Almost all mothers who participated in the questionnaire likewise indicated that they had received nutritional counselling and breast feeding information during antenatal visits. (Some interviewees even praised the health education, nutrition workshops and social support they received from the health facilities and their networks of community health workers.) In the final analysis, therefore, it appears that structural factors, not poor knowledge or insufficient health education, were the key determinants of suboptimal nutrition and feeding practices. Indeed, this structural violence was corroborated by the testimonies of clinicians and social workers, who pointed out how material deprivation forced mothers to make decisions that they knew might harm their child's nutritional health.

This finding calls into question the utility of behaviour change and health education campaigns that do not seek to concurrently alleviate the structural barriers to complying with received instructions. ${ }^{67}$ While there is a case for expanding health education to address some misconceptions on child feeding in Liberia, such as the idea that colostrum is detrimental to an infant's health, the overwhelming majority of interviewees described malnutrition and suboptimal practices as consequences of rampant poverty, food insecurity, the nature of formal and informal work, and the lack of social support and social protection. ${ }^{68}$

Additionally, our findings demonstrate an inverse association between maternal general literacy and child malnutrition. Whereas the level of education attained by a mother was not significantly associated with child nutritional status in the multivariate model, literate mothers were less likely to have malnourished children. This is a particularly noteworthy finding, for it suggests that quality, not simply quantity, of female education may pay greater dividends for child nutrition and well-being. It is not uncommon, for instance, to find secondary school students in rural Liberia who cannot read. Adult female literacy (15 years and older) is only $34 \%$ nationally, approximately half the rate of adult male literacy. ${ }^{69}$ General literacy and maternal education have been linked to improved health outcomes in a variety of settings. ${ }^{70-74}$ In the Liberian context, as in other parts of the world, it is likely that literacy influences gendered power imbalances in ways that are beneficial to maternal and child wellbeing. For example, as we observed through in-depth interviews, literate and well-educated mothers may enjoy greater autonomy, social status and decision-making authority within families and societies, allowing them to better negotiate childcare and feeding practices for the welfare of children. Literacy is also believed to increase women's access to economic opportunities and meaningful employment and their utilisation of healthcare services. ${ }^{72} 75$ Although the quantitative data suggested that literacy shapes nutrition outcomes, this was not noted qualitatively by mothers, who often pointed out they had the correct 'knowledge' for prevention. Thus, literacy serves as a form of power whose mechanisms of malnutrition prevention cannot be reduced to the mere reading of clinic posters. Rather, in the Foucauldian 
sense, it promotes a distinct subjectivity that transcends certain material constraints.

In the quantitative analysis, marital status was also associated with the risk of severe acute malnutrition: interestingly, mothers in our study who were married or in a domestic partnership were more likely to have a malnourished child. While several studies from Africa have reported the opposite finding, the literature on the relationships among marital status, infant and child feeding practices and child health is mixed, suggesting that these relationships are context-specific and socioculturally complex. ${ }^{66}{ }^{77-80}$ As this was a case-control study with a convenience sample, chance or confounding variables or biases not captured by the study may also account for this association.

We therefore explored this finding qualitatively as well and observed that single mothers in Maryland County were often more likely to have extended family support, including resources for food and childcare. On the other hand, several women who were married bemoaned that their spouses had their own extended families to support, leaving little for the nuclear family and placing increased financial onus on their female partners. Some also noted that their husbands would take the proverbial lion's share of meals, further reducing the amounts available to children. Married mothers further explained that their choices and behaviours regarding child/family feeding (including their engagement in breast feeding) were heavily influenced by their families, especially by male partners, and that gender-associated power imbalances constrained their ability to unilaterally make sound decisions for their child's nutrition-circumstances consistent with those documented in a study done in Ghana. ${ }^{81}$ In Liberia, health information on maternal and child nutrition often fails to contend with the pervasiveness of gender inequity in societies; counselling on breast feeding is generally disseminated exclusively to pregnant women or mothers, even though their capacity to comply is dictated by the desires and choices of male figures and elders.

This conclusion aligns with the findings of a study that used data from Liberia's 2007 Demographic and Health Survey to investigate the association between women's lack of empowerment and utilisation of healthcare: Liberian women who were married were less likely to have accessed care (for themselves or their children) at a formal health facility in the preceding year, as were women who had reported a history of sexual abuse. Conversely, women who had greater decision-making power-as measured by respondents' assessment of their say in making five specific household decisions relating to family finances and social interactions-had greater odds of having been to a health facility. ${ }^{82}$ Gender power imbalances, which are prevalent in Liberia (as in much of the world), are thus thought to critically influence maternal and child healthpromoting behaviours. Health literacy initiatives might encourage mothers to practise certain behaviours, but their utility is limited if they do not yield buy-in from male partners and elders; promote female empowerment and agency within and beyond the household; and mediate the social, economic and political dynamics dictating what women are permitted to do.

In the questionnaire, women who stated that they exclusively breast fed for the first 6 months of life were less likely to have a malnourished child than mothers who did not. It is worth noting that $81 \%$ of mothers surveyed in our study stated that they had exclusively breast fed during the first 6 months, including $70 \%$ of mothers of malnourished children. However, in-depth interviews indicated that this result may suffer from social desirability bias or acquiescence bias, as most mothers of malnourished children who were interviewed (and many mothers of non-malnourished ones) expressed social and economic barriers to exclusive breast feeding and explained that they could not adhere to the practice. Regardless, the health benefits of breast feeding are scientifically well supported ${ }^{83}$ and universally endorsed by national and international health authorities. ${ }^{84}$ In lowincome countries, babies who are formula fed or prematurely introduced to solid foods are often at greater risk of malnutrition for a variety of reasons, including household expenditures on formula, dilution of formula (to save powder) and increased diarrhoeal morbidity secondary to contaminated water and poor sanitation. ${ }^{85-89}$

Nutritional education and social support provided during antenatal care, encouragement from peers, and outreach and screening efforts led by community health workers were strong motivations for opting to bring children with severe acute malnutrition to government health facilities. Many mothers said that positive experiences and impressions of JJ Dossen Hospital and Pleebo Health Center were pivotal to their decisions to seek medical care for malnutrition at these facilities. This finding is notable, particularly in the aftermath of a devastating Ebola epidemic that undermined trust between the health authorities and the poor majority, ${ }^{90}$ for it suggests that investments in strengthening health systems for a range of conditions (as has occurred at JJ Dossen Hospital and Pleebo Health Center since the epidemic) can increase patients' confidence in the health system and thus benefit malnutrition care and outcomes. ${ }^{91-93}$ Community health workers and peer groups, as well as traditional healers and prophets, were found to be important resources for the early identification of severe acute malnutrition and for referral to care. These individuals leveraged integration within their communities to create effective, contextspecific messages that helped mothers detect signs of malnutrition and present to health facilities. Our findings support the case for increased investments in these cadres of health workers (formal and informal) and for similar community-based screening and outreach initiatives in regions with high burdens of acute malnutrition. ${ }^{94}$

Finally, therapeutic pluralism and complex notions of disease aetiology also figured into understandings of and responses to child malnutrition. Importantly, although mothers frequently attributed malnutrition to witchcraft, 
most did not view biomedical and traditional healing as mutually exclusive options. Indeed, in recounting their quests for therapy, ${ }^{95}$ many mothers indicated that they concurrently sought care from multiple providers and from multiple sectors, often more than once. That is, whether a mother brought a malnourished child to the health facility did not appear to be correlated with her individual views about the biomedical and/or supernatural causes of her child's illness, as has been observed in other settings and for other pathologies. ${ }^{96}$ Shame associated with material privation was found to be a much more potent reason for delaying treatment than divergent aetiological beliefs or recourse to traditional healing. Church yards and traditional healing systems therefore represent valuable resources for community engagement, referral and partnership in the fight against malnutrition in Liberia.

\section{Limitations}

The study was conducted at two government health facilities in Maryland County and used a convenience sample. Therefore, the findings may not be generalisable to the entire rural population of mothers, children and health workers in Liberia. For example, although Partners In Health has a strong community health worker programme for disease surveillance, it is likely that some malnourished children in Maryland County are not brought to the health facility for diagnosis and care. Since the convenience sample was recruited via clinicians who had evaluated the children at either facility, it did not include children and mothers who had not presented for facility-based care; therefore, selection bias must be considered when assessing external validity. Additionally, the health facilities at which this study was conducted-J J Dossen Hospital and Pleebo Health Center-have been supported by the medical non-profit Partners In Health for over several years and have documented significant improvements in quality of services and clinical outcomes for various conditions. ${ }^{97} 98$ Many other government facilities in rural Liberia have not received similar support, which may introduce differences in communities' perceptions of their health facilities, the amount of food and nutritional support patients receive, their decisions to seek treatment for acute malnutrition and other factors. The findings of the questionnaire must also be considered correlational, and common limitations associated with surveys, convenience sampling and case-control study designs are applicable, including sampling bias, confounders, recall bias and other types of response bias.

\section{CONCLUSIONS}

To drive down the burden of paediatric malnutrition in Liberia, the government and its partners should continue to improve access to and quality of formal education, especially among women and girls. Legislation for more robust and equitable maternity protection, childcare and workplace support for breast feeding should be introduced and enforced. ${ }^{13}$ Given Liberia's large informal work sectors, however, it is equally necessary to provide social protection measures that are suitable for the poorest Liberian women. Cash transfers and direct food support to new mothers, for example, may alleviate the commonly cited economic constraints on optimal infant and child feeding. Behaviour change and health education interventions may be helpful in particular scenarios and formats, such as to correct common misconceptions (eg, about colostrum); however, only through a strong commitment to combating structural violence and the transnational relations of inequity that engender it $^{99100}$ is Liberia likely to achieve meaningful reductions in malnutrition.

Twitter Eugene T Richardson @Real_Ironist

Acknowledgements We are grateful to the participants of this study, including mothers within the catchment areas of $\mathrm{J} J$ Dossen Hospital and Pleebo Health Center and facility-based health workers working at these sites in south-eastern Liberia. We also thank the Ministry of Health of Liberia for its partnership and its leadership of the health system in Maryland County. Lastly, we thank the staff of Partners In Health for its dedication to global health equity.

Contributors OWK, MPF and ETR designed the study. OWK, IKD, HNG, JBS and ETR conducted the literature search. OWK collected the data. OWK, MPF, IKD, HNG, JBS, $\mathrm{SB}, \mathrm{JB}, \mathrm{JS} M$ and ETR interpreted the results. OWK and IKD wrote the article. OWK, MPF, IKD, HNG, JBS, SB, JB, JSM and ETR edited and revised the article.

Funding This research was made possible with the support of Harvard Medical School and the Ministry of Health of Liberia.

Competing interests None declared.

Patient consent for publication Not required.

Ethics approval Study protocols were approved by the Harvard Medical School Institutional Review Board and the National Research Ethics Board of Liberia. Informed consent was read verbatim by the first author, and all enrolled participants indicated consent through either a signature or thumb print. All research was conducted in accordance with the Helsinki Declaration guidelines.

Provenance and peer review Not commissioned; externally peer reviewed.

Data availability statement Data are available upon reasonable request.

Open access This is an open access article distributed in accordance with the Creative Commons Attribution Non Commercial (CC BY-NC 4.0) license, which permits others to distribute, remix, adapt, build upon this work non-commercially, and license their derivative works on different terms, provided the original work is properly cited, appropriate credit is given, any changes made indicated, and the use is non-commercial. See: http://creativecommons.org/licenses/by-nc/4.0/.

ORCID iD

Eugene T Richardson http://orcid.org/0000-0001-8437-0671

\section{REFERENCES}

1 United Nations Human Rights Council. Universal Declaration on the eradication of hunger and malnutrition. Rome: Office of the High Commissioner for Human Rights, 1974. https://www.ohchr.org/EN/ Professionallnterest/Pages/EradicationOfHungerAndMalnutrition. aspx

2 World Food Summit. Rome Declaration on world food security. Rome: FAO, 1996. http://www.fao.org/docrep/003/w3613e/ w3613e00.htm

3 United Nations General Assembly. Transforming our world: the 2030 agenda for sustainable development (resolution 70/1). New York: United Nations, 2015. https://sustainabledevelopment.un.org/ post2015/transformingourworld

4 Food and Agriculture Organization of the United Nations, World Health Organization. United nations decade of action on nutrition, 2016-2025: towards Country-Specific smart commitments for action on nutrition. Rome: FAO, 2016. http://www.fao.org/3/a-i6130e.pdf 
5 Food and Agriculture Organization of the United Nations. World hunger on the rise again, reversing years of progress. Rome: FAO, 2017. http://www.fao.org/news/story/en/item/902489/icode/

6 United Nations Children's Fund. The State of the World's Children 2008: Child Survival. New York: UNICEF, 2007.

7 de Onis M, Branca F. Childhood stunting: a global perspective. Matern Child Nutr 2016;12 Suppl 1:12-26.

8 Adair LS, Fall CHD, Osmond C, et al. Associations of linear growth and relative weight gain during early life with adult health and human capital in countries of low and middle income: findings from five birth cohort studies. Lancet 2013;382:525-34.

9 Black RE, Victora CG, Walker SP, et al. Maternal and child undernutrition and overweight in low-income and middle-income countries. Lancet 2013;382:427-51.

10 Victora CG, Adair L, Fall C, et al. Maternal and child undernutrition: consequences for adult health and human capital. Lancet 2008;371:340-57.

11 World Health Organization. Infant and young child feeding. Geneva: WHO, 2018. https://www.who.int/news-room/fact-sheets/detail/ infant-and-young-child-feeding

12 Bhutta ZA, Das JK, Rizvi A, et al. Evidence-Based interventions for improvement of maternal and child nutrition: what can be done and at what cost? Lancet 2013;382:452-77.

13 Rollins NC, Bhandari N, Hajeebhoy N, et al. Why invest, and what it will take to improve breastfeeding practices? Lancet 2016;387:491-504.

14 World Bank Group, Results for Development, 1000 Days, Children's Investment Fund Foundation, Bill and Melinda Gates Foundation. Reaching the global target to reduce stunting: how much will it cost and how can we pay for it? Washington, DC: World Bank Group, 2015. http://pubdocs.worldbank.org/en/460861439997767818/ Stunting-Costing-and-Financing-Overview-Brief.pdf

15 Institute for Health Metrics and Evaluation. GBD profile: Liberia. Institute for health metrics and evaluation. Available: http://www. healthdata.org/sites/default/files/files/country_profiles/GBD/ihme gbd_country_report_liberia.pdf

16 Liberia Institute of Statistics Geo-Information Services (LISGIS), Ministry of Health and Social Welfare (Liberia), National AIDS Control Program (Liberia), ICF International. Liberia demographic and health survey 2013. Monrovia, Liberia: LISGIS and ICF International, 2014.

17 Veeken H. Thousands starving in Liberia. BMJ 1993;307:628.

18 Doocy S, Lewy D, Guenther T, et al. Mortality, nutrition and health in Lofa County Liberia five years post-conflict. World Health Popul 2010;12:23-33.

19 Gatiso TT, Ordaz-Németh I, Grimes T, et al. The impact of the Ebola virus disease (EVD) epidemic on agricultural production and livelihoods in Liberia. PLoS Negl Trop Dis 2018;12:e0006580.

20 Kamara MH, Najjemba R, van Griensven J, et al. Increase in acute malnutrition in children following the 2014-2015 Ebola outbreak in rural Sierra Leone. Public Health Action 2017;7:27-33.

21 Kodish SR, Bio F, Oemcke R, et al. A qualitative study to understand how Ebola virus disease affected nutrition in Sierra Leone-A food value-chain framework for improving future response strategies. PLoS Negl Trop Dis 2019;13:e0007645.

22 Oche MO, Umar AS, Ahmed H. Knowledge and practice of exclusive breastfeeding in Kware, Nigeria. Afr Health Sci 2011;11:518-23.

23 Iliyasu Z, Galadanci HS, Emokpae P, et al. Predictors of exclusive breastfeeding among health care workers in urban Kano, Nigeria. $J$ Obstet Gynecol Neonatal Nurs 2019;48:433-44.

24 Lucas A, McMahon PM, Asling MB, et al. Assessing child care providers' knowledge and attitudes regarding support of breastfeeding in a region with low breastfeeding prevalence. J Hum Lact 2013;29:556-63.

25 Nukpezah RN, Nuvor SV, Ninnoni J. Knowledge and practice of exclusive breastfeeding among mothers in the tamale Metropolis of Ghana. Reprod Health 2018;15:140.

26 Iliyasu Z, Galadanci HS, lliyasu ML, et al. Determinants of infant feeding practices among HIV-infected mothers in urban Kano, Nigeria. J Hum Lact 2019;35:592-600.

27 Dietrich Leurer M, Petrucka P, Msafiri M. Maternal perceptions of breastfeeding and infant nutrition among a select group of Maasai women. BMC Pregnancy Childbirth 2019;19:8.

28 Odu S, Deji SA, Amu E. Knowledge, attitude and practice of exclusive breastfeeding among mothers attending an infant welfare clinic in Osogbo, Osun state, Nigeria. Eur J Prev Cardiol 2016;4:39-43.

29 Mogre V, Dery M, Gaa PK, Knowledge GPK. Knowledge, attitudes and determinants of exclusive breastfeeding practice among Ghanaian rural lactating mothers. Int Breastfeed J 2016;11:12.
30 Ulak M, Chandyo RK, Mellander L, et al. Infant feeding practices in Bhaktapur, Nepal: a cross-sectional, health facility based survey. Int Breastfeed J 2012;7:1.

31 Chiutsi-Phiri G, Heil E, Kalimbira AA, et al. Reduced morbidity motivated adoption of infant and young child feeding practices after nutrition education intervention in rural Malawi. Ecol Food Nutr 2017:56:329-48.

32 Leshi O, Samuel FO, O. Ajakaye M, et al. Breastfeeding knowledge, attitude and intention among female young adults in Ibadan, Nigeria. Open J Nurs 2016;06:11-23.

33 Iliyasu Z, Kabir M, Abubakar I, et al. Current knowledge and practice of exclusive breastfeeding among mothers in Gwale local government area of Kano state. Niger Med Pract 2005;48:50-5.

34 Talbert AW, Tsofa B, Mumbo E, et al. Knowledge of, and attitudes to giving expressed breastmilk to infants in rural coastal Kenya; focus group discussions of first time mothers and their advisers. Int Breastfeed J 2018;13:16.

35 Ezechukwu CC, Egbuonu I, Ugochukwu EF, et al. Maternal attitudes to breast feeding in the concept of the baby friendly Hospital initiative. J Biomed Invest;2:82-5.

36 Aborigo RA, Moyer CA, Rominski S, et al. Infant nutrition in the first seven days of life in rural Northern Ghana. BMC Pregnancy Childbirth 2012;12:76.

37 Okolo SN, Adewunmi YB, Okonji MC. Current breastfeeding knowledge, attitude, and practices of mothers in five rural communities in the savannah region of Nigeria. $J$ Trop Pediatr 1999;45:323-6.

38 Tawiah-Agyemang C, Kirkwood BR, Edmond K, et al. Early initiation of breast-feeding in Ghana: barriers and facilitators. $J$ Perinatol 2008;28 Suppl 2:S46-52.

39 Sadoh AE, Sadoh WE, Oniyelu P. Breast feeding practice among medical women in Nigeria. Niger Med J 2011;52:7-12.

40 Utoo BT, Ochejele S, Obulu MA, et al. Breastfeeding knowledge and attitudes amongst health workers in a health care facility in South-South Nigeria: the need for middle level health manpower development. Clin Mother Child Health 2012;9:1-5.

41 Gewa CA, Chepkemboi J. Maternal knowledge, outcome expectancies and normative beliefs as determinants of cessation of exclusive breastfeeding: a cross-sectional study in rural Kenya. BMC Public Health 2016;16:243.

42 Mbada CE, Olowookere AE, Faronbi JO, et al. Knowledge, attitude and techniques of breastfeeding among Nigerian mothers from a semi-urban community. BMC Res Notes 2013;6:552.

43 Anyanechi $\mathrm{CE}$, Ekabua KJ, Ekpenyong AB, et al. Parturients awareness and perception of benefits of breast feeding in the prevention of infant and childhood oral and dental diseases. Ghana Med J 2017;51:83-7.

44 Karmbor-Ballah EG, Fallah MP, Silverstein JB, et al. Maternal mortality and the metempsychosis of user fees in Liberia: a mixedmethods analysis. Scientific African 2019;3:e00050.

45 Creswell JW, Plano Clark VL. Designing and conducting mixed methods research. 3rd ed. Los Angeles: SAGE, 2017.

46 World Health Organization,, UNICEF. Who child growth standards and the identification of severe acute malnutrition in infants and children. Geneva: WHO, 2009.

47 World Health Organization. Identification of severe acute malnutrition in infants under 6 months of age. Geneva: WHO, 2019. https://www.who.int/elena/titles/sam_identification_infants/en/

48 World Health Organization. Supplementary foods for the management of moderate acute malnutrition in children aged 6-59 months. Geneva: WHO, 2019. https://www.who.int/elena/titles/ food_children mam/en/

49 Bursac Z, Gauss CH, Williams DK, et al. Purposeful selection of variables in logistic regression. Source Code Biol Med 2008;3:17.

50 Hsieh H-F, Shannon SE. Three approaches to qualitative content analysis. Qual Health Res 2005;15:1277-88.

51 Abramowitz S. What Happens When MSF Leaves? Humanitarian Departure and Medical Sovereignty in Postconflict Liberia. In: Abramowitz S, Panter-Brick C, Piot P, eds. Medical Humanitarianism: Ethnographies of practice. Philadelphia: University of Pennsylvania Press, 2015: 137-54.

52 Abramowitz SA. Searching for normal in the wake of the Liberian war. Philadelphia: University of Pennsylvania Press, 2014.

53 Benton A, Dionne KY. International political economy and the 2014 West African Ebola outbreak. Afr Stud Rev 2015;58:223-36.

54 Hahn N. Us covert and overt operations in Liberia, 1970s to 2003. ASPJ Africa and Francophonie 2014;5:19-47.

55 Hickel J. The divide: global inequality from conquest to free markets. New York: W.W: Norton \& Company, 2018.

56 Kentikelenis A, King L, McKee M, et al. The International monetary fund and the Ebola outbreak. Lancet Glob Health 2015;3:e69-70. 
57 Keshavjee S. Blind spot: how Neoliberalism infiltrated global health. University of California Press: Oakland, 2014.

58 GK KJ. The first Liberian civil war: the crises of Underdevelopment. New York: Peter Lang, 2008

59 Kruk ME, Rockers PC, Williams EH, et al. Availability of essential health services in post-conflict Liberia. Bull World Health Organ 2010;88:527-34.

60 Mayson DT-W, Sawyer A. Labour in Liberia. Rev Afr Polit Econ 1979;6:3-15.

61 Shakow A, Yates R, Keshavjee S. Neoliberalism and Global Health. In: Cahill D, Cooper M, Konings M, et al, eds. The SAGE Handbook of Neoliberalism. London: SAGE Publications, 2018: 511-36.

62 Bliss J, Jensen N, Thiede B, et al. Factors associated with the risk of acute malnutrition among children aged 6 to 36 months in households targeted by an emergency cash transfer program. Food Nutr Bull 2016;37:387-400.

63 Goudet SM, Kimani-Murage EW, Wekesah F, et al. How does poverty affect children's nutritional status in Nairobi slums? A qualitative study of the root causes of undernutrition. Public Health Nutr 2017;20:608-19.

64 Harimbola DR, Mizumoto K. Individual and household risk factors for severe acute malnutrition among Under-Five children in the Analamanga region, Madagascar. Int J MCH AIDS 2018;7:217-25.

65 Kimani-Murage EW, Wekesah F, Wanjohi M, et al. Factors affecting actualisation of the who breastfeeding recommendations in urban poor settings in Kenya. Matern Child Nutr 2015;11:314-32.

66 Tette EMA, Sifah EK, Nartey ET, et al. Maternal profiles and social determinants of malnutrition and the MDGs: what have we learnt? BMC Public Health 2016;16:214.

67 Farmer P. Social scientists and the new tuberculosis. Soc Sci Med 1997;44:347-58.

68 Richardson ET, Kelly JD, Sesay O, et al. The symbolic violence of 'outbreak': A mixed methods, quasi-experimental impact evaluation of social protection on Ebola survivor wellbeing. Soc Sci Med 2017:195:77-82.

69 UNESCO Institute of Statistics. Liberia. Montreal: UNESCO, 2020. Available: http://uis.unesco.org/en/country/lr

70 Gakidou E, Cowling K, Lozano R, et al. Increased educational attainment and its effect on child mortality in 175 countries between 1970 and 2009: a systematic analysis. The Lancet 2010;376:959-74

71 Grosse RN, Auffrey C. Literacy and health status in developing countries. Annu Rev Public Health 1989;10:281-97.

72 Kateja A. Role of female literacy in maternal and infant mortality decline. Soc Change 2007;37:29-39.

73 Pillai VK, Maleku A, Wei F. Maternal mortality and female literacy rates in developing countries during 1970-2000: a latent growth curve analysis. Int J Popul Res 2013;2013:1-11.

74 Sandiford P, Cassel J, Montenegro M, et al. The Impact of Women's Literacy on Child Health and its Interaction with Access to Health Services. Popul Stud 1995;49:5-17.

75 Cleland JG, Van Ginneken JK. Maternal education and child survival in developing countries: the search for pathways of influence. Soc Sci Med 1988;27:1357-68.

76 Levine RA, Rowe ML. Maternal literacy and child health in lessdeveloped countries: evidence, processes, and limitations. J Dev Behav Pediatr 2009;30:340-9.

77 Ickes SB, Hurst TE, Flax VL. Maternal literacy, facility birth, and education are positively associated with better infant and young child feeding practices and nutritional status among Ugandan children. J Nutr 2015;145:2578-86.

78 Kimani-Murage EW, Madise NJ, Fotso J-C, et al. Patterns and determinants of breastfeeding and complementary feeding practices in urban informal settlements, Nairobi Kenya. BMC Public Health 2011:11:396.
79 Ntoimo LFC, Odimegwu CO. Health effects of single motherhood on children in sub-Saharan Africa: a cross-sectional study. BMC Public Health 2014;14:1145.

80 Potocka A, Jacukowicz A. Differences in nutritional status of preschool children in the context of the maternal social characteristics. Int J Occup Med Environ Health 2017;30:811-21.

81 Mensah KA, Acheampong E, Anokye FO, et al. Factors influencing the practice of exclusive breastfeeding among nursing mothers in a peri-urban district of Ghana. BMC Res Notes 2017;10:466.

82 Sipsma H, Callands TA, Bradley E, et al. Healthcare utilisation and empowerment among women in Liberia. J Epidemiol Community Health 2013;67:953-9.

83 Victora CG, Bahl R, Barros AJD, et al. Breastfeeding in the 21st century: epidemiology, mechanisms, and lifelong effect. Lancet 2016;387:475-90.

84 World Health Organization. The optimal duration of exclusive breastfeeding: report of the expert consultation. Geneva: WHO, 2002.

85 Black RE, Allen LH, Bhutta ZA, et al. Maternal and child undernutrition: global and regional exposures and health consequences. Lancet 2008;371:243-60.

86 Fawzy A, Arpadi S, Kankasa C, et al. Early weaning increases diarrhea morbidity and mortality among uninfected children born to HIV-infected mothers in Zambia. J Infect Dis 2011;203:1222-30.

87 Haider R, Islam A, Kabir I, et al. Early complementary feeding is associated with low nutritional status of young infants recovering from diarrhoea. J Trop Pediatr 1996;42:170-2.

88 Lamberti LM, Fischer Walker CL, Noiman A, et al. Breastfeeding and the risk for diarrhea morbidity and mortality. BMC Public Health 2011;11 Suppl 3:S15.

89 Ogbo FA, Agho K, Ogeleka P, et al. Infant feeding practices and diarrhoea in sub-Saharan African countries with high diarrhoea mortality. PLoS One 2017;12:e0171792.

90 Richardson ET. On the coloniality of global public health. MAT 2019;6:101-18.

91 Blair RA, Morse BS, Tsai LL. Public health and public trust: survey evidence from the Ebola virus disease epidemic in Liberia. Soc Sci Med 2017;172:89-97.

92 Jones T, Ho L, Kun KK, et al. Rebuilding people-centred maternal health services in post-Ebola Liberia through participatory action research. Glob Public Health 2018;13:1650-69.

93 Morse B, Grépin KA, Blair RA, et al. Patterns of demand for non-Ebola health services during and after the Ebola outbreak: panel survey evidence from Monrovia, Liberia. BMJ Glob Health 2016;1:e000007.

94 Majamanda J, Maureen D, Munkhondia TM, et al. The effectiveness of community-based nutrition education on the nutrition status of Under-five children in developing countries. A systematic review. Malawi Med J 2014;26:115-8.

95 Janzen JM. The quest for therapy in lower Zaire. Berkeley: University of California Press, 1978.

96 Farmer P. Infections and inequalities: the modern plagues. Berkeley: University of California Press, 1999

97 Wickett E, Peralta-Santos A, Beste J, et al. Treatment outcomes of TB-infected individuals attending public sector primary care clinics in rural Liberia from 2015 to 2017: a retrospective cohort study. Trop Med Int Health 2018;23:549-57.

98 Joharifard S, Price N, Ipanaqué JGY, et al. The impact of implementing a comprehensive surgical program on the surgica cohort at a remote referral hospital in southeastern Liberia. World $J$ Surg 2020;44:680-8.

99 Farmer P. An anthropology of structural violence. Curr Anthropol 2004;45:305-25.

100 Richardson ET, Barrie MB, Kelly JD, et al. Biosocial approaches to the 2013-2016 Ebola pandemic. Health Hum Rights 2016:18:115-28. 